\title{
EXTENSIONS AND REFINEMENTS OF FEJER AND HERMITE-HADAMARD TYPE INEQUALITIES
}

\author{
Shoshana ABramovich AND LARS-ERIK PERSSON
}

Abstract. In this paper extensions and refinements of Hermite-Hadamard and Fejer type inequalities are derived including monotonicity of some functions related to the Fejer inequality and extensions for functions, which are 1 -quasiconvex and for function with bounded second derivative. We deal also with Fejer inequalities in cases that $p$, the weight function in Fejer inequality, is not symmetric but monotone on $[a, b]$.

\section{Mathematics subject classification (2010): 26D15.}

Keywords and phrases: Fejer inequality, Hermite-Hadamard inequality, convexity, $N$-quasiconvexity.

\section{REFERENCES}

[1] S. Abramovich Hölder, Jensen, Minkowski, Jensen-Steffensen and Slater-Pečarić inequalities derived through N-quasiconvexity, Math. Inequal. Appl. 19, 4 (2016), 1203-1226.

[2] S. Abramovich, J. BARIĆ AND J. PeČArić, Fejer and Hermite-Hadamard type inequalities for superquadratic functions, J. Math. Anal. Appl. 344, 2 (2008), 1048-1056.

[3] S. Abramovich and L.-E. Persson, Fejer and Hermite-Hadamard type inequalities for $\mathrm{N}$ quasiconvex functions, Math. Notes 102, 5 (2017), 599-609.

[4] S. Abramovich AND L.-E. Persson, Some new estimates of the 'Jensen gap', JIAP, J. Inequal. Appl. 2016, 39 (2016), 9 pp.

[5] F. CHEN, Extension of the Hermite-Hadamard inequality for convex functions via fractional integrals, J. Math. Inequal. 10, 1 (2016), 75-81.

[6] B. G. PachPatte, On some inequalities for convex functions, Research Group in Mmathematical Inequalities and Applications 6, 1 (2003), 8 pp. 